\title{
Sodium-glucose cotransporter-2 inhibitor for renal function preservation in patients with type 2 diabetes mellitus: a Korean Diabetes Association and Korean Society of Nephrology consensus statement
}

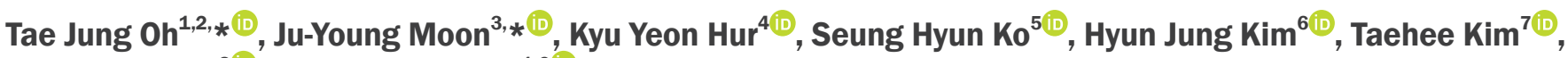 \\ Dong Won Lee ${ }^{8(\mathbb{1})}$, Min Kyong Moon ${ }^{1,9}$, The Committee of Clinical Practice Guideline, Korean Diabetes \\ Association and Committee of the Cooperative Studies, Korean Society of Nephrology \\ 'Department of Internal Medicine, Seoul National University College of Medicine, Seoul, Republic of Korea \\ 2Department of Internal Medicine, Seoul National University Bundang Hospital, Seongnam, Republic of Korea \\ ${ }^{3}$ Division of Nephrology, Department of Internal Medicine, Kyung Hee University School of Medicine, Seoul, Republic of Korea \\ ${ }^{4}$ Division of Endocrinology and Metabolism, Department of Medicine, Samsung Medical Center, Sungkyunkwan University School of \\ Medicine, Seoul, Republic of Korea \\ ${ }^{5}$ Division of Endocrinology and Metabolism, Department of Internal Medicine, St. Vincent's Hospital, College of Medicine, The Catholic \\ University of Korea, Suwon, Republic of Korea \\ ${ }^{6}$ Department of Preventive Medicine, Korea University College of Medicine, Seoul, Republic of Korea \\ ${ }^{7}$ Division of Nephrology, Department of Internal Medicine, Inje University Busan Paik Hospital, Inje University School of Medicine, \\ Busan, Republic of Korea \\ ${ }^{8}$ Division of Nephrology, Department of Internal Medicine, Pusan National University School of Medicine, Yangsan, Republic of Korea \\ ${ }^{9}$ Department of Internal Medicine, Seoul Metropolitan Government Seoul National University Boramae Medical Center, Seoul, \\ Republic of Korea
}

Diabetes is a leading cause of end-stage renal disease. Therefore, prevention of renal dysfunction is an important treatment goal in the management of diabetes. The data of landmark cardiovascular outcome trials of sodiumglucose cotransporter-2 (SGLT2) inhibitors showed profound reno-protective effects. The Korean Diabetes Association and the Korean Society of Nephrology reviewed clinical trials and performed a meta-analysis to assess the effects of

Received July 21, 2020; Revised August 7, 2020; Accepted August 9, 2020

Editor: Soo Wan Kim, Chonnam National University, Gwangju, Republic of Korea

Correspondence:

Dong Won Lee

Division of Nephrology, Department of Internal Medicine, Pusan National University School of Medicine, 20 Geumo-ro, Mulgeumeup, Yangsan 50612, Republic of Korea. E-mail: dongwonlee@pusan.ac.kr

Min Kyong Moon

Division of Endocrinology and Metabolism, Department of Internal Medicine, Seoul Metropolitan Government Seoul National University Boramae Medical Center, Seoul National University College of Medicine, 20 Boramae-ro 5-gil, Dongjak-gu, Seoul o7061, Republic of Korea. E-mail:mkmoon@snu.ac.kr

*Tae Jung Oh and Ju-Young Moon contributed equally to this study as co-first authors.

This manuscript has been simultaneously published in the Diabetes \& Metabolism Journal and in Kidney Research and Clinical Practice by the Korean Diabetes Association and the Korean Society of Nephrology.

Copyright (C) 2020 by The Korean Society of Nephrology

(a) This is an open-access article distributed under the terms of the Creative Commons Attribution Non-Commercial License (http://creativecommons.org/ licenses/by-nc-nd/4.0/), which permits unrestricted non-commercial use, distribution, and reproduction in any medium, provided the original work is properly cited. 
SGLT2 inhibitors on the preservation of estimated glomerular filtration rate (eGFR). We limited the data of SGLT2 inhibitors which can be prescribed in Korea. Both eGFR value and its change from the baseline were significantly more preserved in the SGLT2-inhibitor treatment group compared to the control group after 156 weeks. However, some known adverse events were increased in SGLT2 inhibitor treatment, such as genital infection, diabetic ketoacidosis, and volume depletion. We recommend long-term use of SGLT2 inhibitors in patients with type 2 diabetes mellitus (T2DM) for attenuation of renal function decline. However, we cannot generalize our recommendations due to the lack of long-term clinical trials testing the reno-protective effects of every SGLT2 inhibitor in a broad range of patients with T2DM. This recommendation can be revised and updated after the publication of several large-scale renal outcome trials.

Keywords: Diabetes mellitus, type 2, Glomerular filtration rate, Renal function, Sodium-glucose transporter-2 inhibitors

\section{Introduction}

Diabetic kidney disease (DKD) is a global problem and the prevalence and incidence are increasing strikingly. Along with the accelerating incidence of DKD, the total number of patients with end-stage renal disease (ESRD) undergoing maintenance dialysis has grown by approximately $7 \%$ to $10 \%$ per year in Korea [1-3]. DKD is the most prevalent cause of ESRD (affecting $50.2 \%$ of new ESRD patients in 2016) in Korea from 1994 [4]. All current treatment efforts in type 2 diabetes mellitus (T2DM) are devoted to the control of hyperglycemia to prevent the development of micro- and macrovascular complications. The cornerstone of therapy to prevent DKD is the strict control of the blood pressure with the reninangiotensin-aldosterone system (RAAS) blockade and blood glucose levels [5]. However, many patients with diabetes progress to chronic kidney disease (CKD) despite standard treatment. These kinds of patients usually have profound amounts of albuminuria despite the use of RAAS-blocking agents and renal function declines rapidly. Furthermore, reduced estimated glomerular filtration rate (eGFR) is independently associated with allcause mortality and cardiovascular disease [6]. There is an unmet clinical need for diabetes treatment to prevent or delay DKD progression.

Sodium-glucose cotransporter-2 (SGLT2) inhibitor is an emerging antidiabetic medication, and its cardio-protective effects has been proven from the large-scale cardiovascular outcome trials of Empagliflozin Cardiovascular Outcome Event Trial in Type 2 Diabetes (EMPA-REG) OUTCOME [7], Canagliflozin Cardiovascular Assessment Study (CANVAS) Program [8], and Dapagliflozin Effect on Cardiovascular Events-Thrombolysis in Myocardial In- farction 58 (DECLARE-TIMI 58) [9]. In these studies, renal outcome was analyzed as a secondary outcome. Empagliflozin showed a $49 \%$ reduction of incident or worsening of nephropathy (progression to macroalbuminuria, doubling of the serum creatinine level, initiation of renal-replacement therapy, or death from renal disease) [10], and dapagliflozin reduced $47 \%$ of renal-specific outcomes (a sustained decline of at least $40 \%$ in eGFR to less than $60 \mathrm{~mL} / \mathrm{min}$ per $1.73 \mathrm{~m}^{2}$, ESRD, or death from renal or cardiovascular causes) [11]. The Canagliflozin and Renal Endpoints in Diabetes with Established Nephropathy Clinical Evaluation (CREDENCE) trial [12] was the first study to show reno-protective effects as a primary outcome from a large-scale randomized clinical trial (among 4,401 subjects with T2DM). However, canagliflozin is not available in Korea. Therefore, it is necessary to investigate the renal benefits of SGLT2 inhibitors that can be prescribed in Korea [13,14]. In real clinical practice, we monitored patients' renal functions using eGFR as described in other clinical trials assessed it. Therefore, among various renal outcomes, we aimed to analyze the eGFR after long-term treatment with SGLT2 inhibitors.

\section{Recent recommendations regarding SGLT2 inhibitor use in patients with T2DM}

In August 2019, the American Diabetes Association revised the online version of the Standards of Medical Care in Diabetes, adopting the results of the CREDENCE trial [15]. It recommended to consider SGLT2 inhibitor treatment in patients with T2DM and CKD (level of evidence C). After that, it updated the recommendation level to level of evidence A and specified the indication of SGLT2 inhibitor for patients with T2DM and DKD with an eGFR 
of at least $30 \mathrm{~mL} / \mathrm{min}$ per $1.73 \mathrm{~m}^{2}$ and albuminuria in 2020 [16]. Diabetes Canada also recommended SGLT2 inhibitor in T2DM with clinical cardiovascular disease and with an eGFR of at least $30 \mathrm{~mL} / \mathrm{min}$ per $1.73 \mathrm{~m}^{2}$ to reduce the risk of progression of CKD (Grade B, level 2 for empagliflozin and Grade C, level 3 for canagliflozin) in 2018 [17]. The Committee of Clinical Practice Guideline of the Korean Diabetes Association updated to the 6th Clinical Practice Guideline in 2019. In this guideline, SGLT2 inhibitor was recommended as a second-line drug, and the committee emphasized its cardioprotective effects [18]. However, it did not yet contain renal outcomes of SGLT2 inhibitor. In this statement, we firstly announced the reno-protective effects of SGLT2 inhibitor considering the situation of Korea.

\section{Effects of SGLT2 inhibitors on renal function}

\section{Results of cardiovascular outcome trials using SGLT2 inhibitors}

Neuen et al [19] reported the meta-analysis data of EMPA-REG Outcome, CANVAS Program, CREDENCE, and DECLARE-TIMI 58. This meta-analysis demonstrated

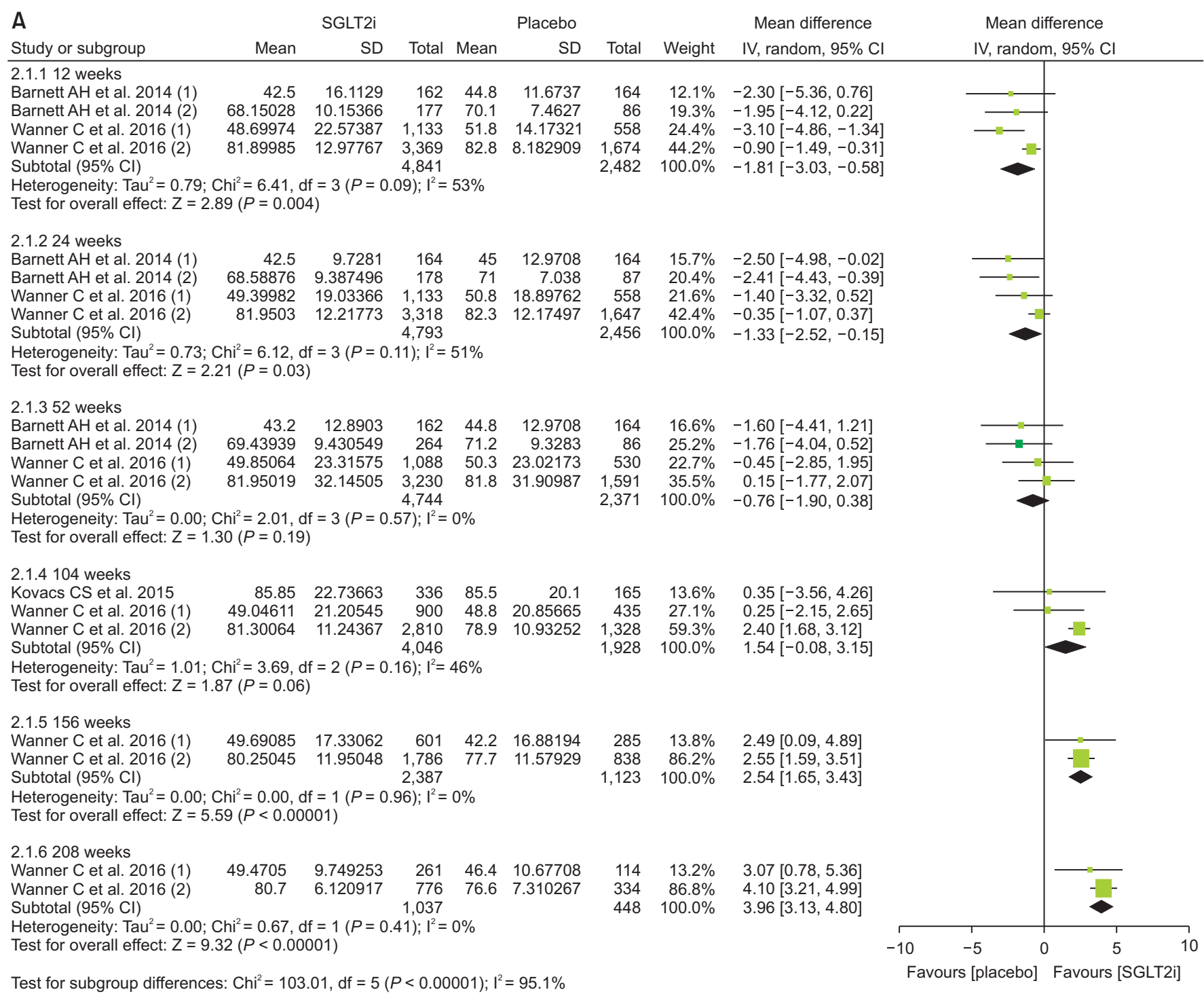

Figure 1. Effect of sodium-glucose cotransporter-2 inhibitors (SGLT2i) on (A) estimated glomerular filtration rate (eGFR), and (B) change of eGFR from baseline.

$\mathrm{Cl}$, confidence interval; IV, inverse variance; SD, standard deviation. 
that SGLT2 inhibitors reduced the risk of ESRD and death due to kidney disease (relative risk of 0.67). This beneficial effect has been shown consistently across baseline eGFR levels in those studies. However, a meta-analysis result excluding the CREDENCE trial showed that the reno-protective effects were attenuated in patients with more advanced renal dysfunction at a baseline eGFR of less than $60 \mathrm{~mL} / \mathrm{min}$ per $1.73 \mathrm{~m}^{2}$ [20]. The inclusion and exclusion criteria of the original randomized clinical tri- als were not the same. For example, the EMPA-REG trial [10] included subjects with their eGFRs of at least $30 \mathrm{~mL} /$ min per $1.73 \mathrm{~m}^{2}$, in contrast the DECLARE-TIMI 58 study [11] included subjects whose eGFRs were equal to or higher than $60 \mathrm{~mL} / \mathrm{min}$ per $1.73 \mathrm{~m}^{2}$. In this regard, 25.5\% of subjects in the EMPA-REG study and only $7.4 \%$ of participants in DECLARE-TIMI 58 had eGFRs that were less than $60 \mathrm{~mL} / \mathrm{min}$ per $1.73 \mathrm{~m}^{2}$. Furthermore, a large number of participants were not followed up, and Asian pa-

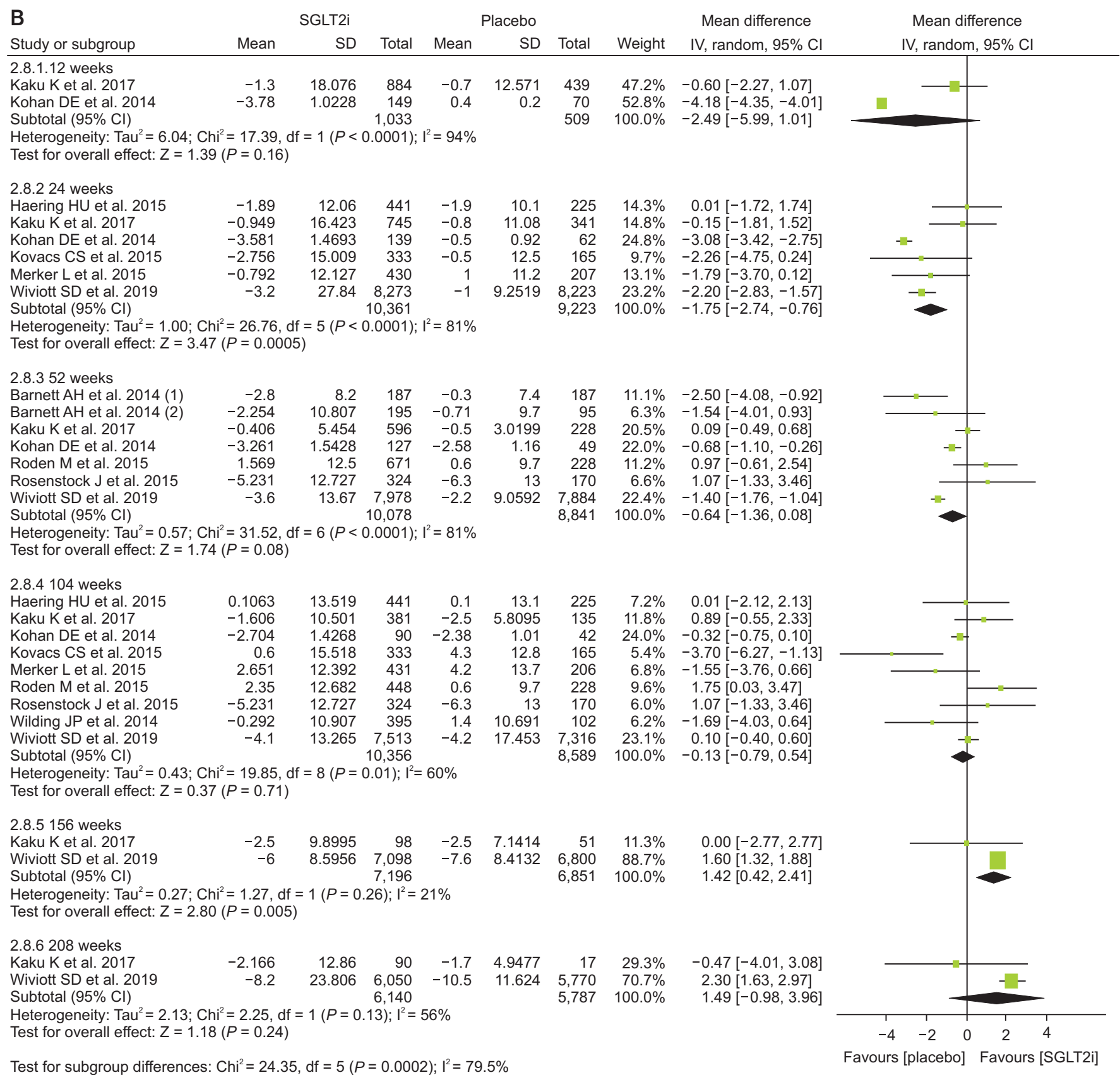

Figure 1. Continued. 
tients made up the minority of participants in each study, including $21.6 \%$ in the EMPA-REG study and $13.4 \%$ in the DECLARE-TIMI 58 study. For this reason, uncertainty remains about the reno-protective effect of SGLT2 inhibitor in Asian populations with reduced renal function. In this study, we reviewed current evidence considering patients' baseline renal function and performed a metaanalysis to determine whether SGLT2 inhibitor can be recommended to Korean subjects with T2DM.

\section{Meta-analysis of large clinical trials using SGLT2 inhibitors}

\section{Search strategy and selection criteria}

We searched PubMed, Embase, and the Cochrane Central Register of Controlled Library up to March 2020, using search terms including "dapagliflozin," "empagliflozin," "ipragliflozin," and "ertugliflozin," which are drugs available in Korea. We included long-term largescale randomized placebo controlled trials whose treatment duration was at least 52 weeks in T2DM patients with more than 100 participants in total. No studies on ipragliflozin and ertugliflozin met these criteria. Finally, we included 12 articles for 11 clinical studies (Supplementary Table 1 and Supplementary Fig. 1, available online) $[9,10,21-30]$. In this meta-analysis, the final eGFR or delta eGFR from baseline was compared between the SGLT2-inhibitor treatment group and placebo-control according to the method presented in the original studies, and we analyzed the data of low and high doses of empagliflozin separately.

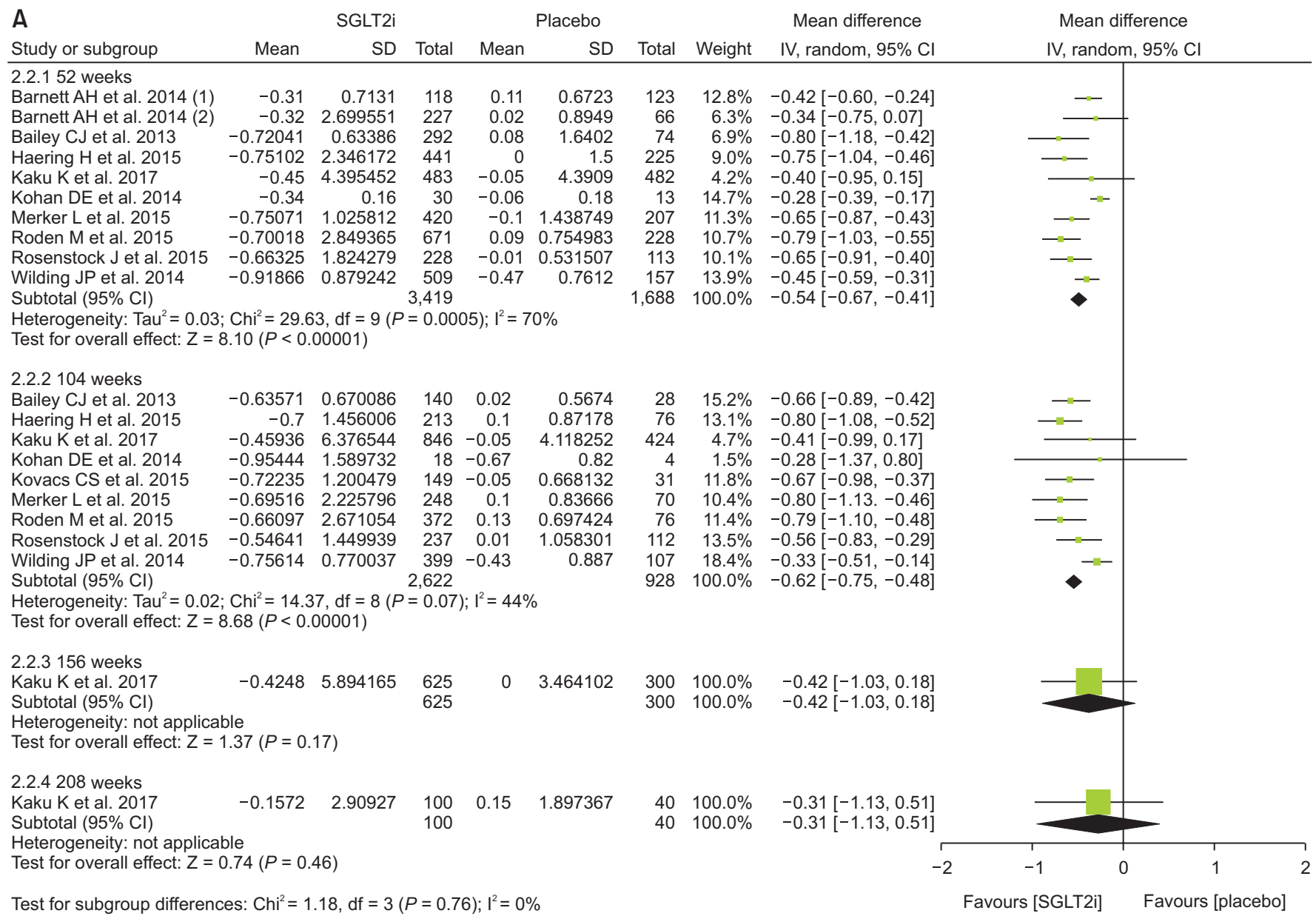

Figure 2. Effect of sodium-glucose cotransporter-2 inhibitors (SGLT2i) on change of (A) glycosylated hemoglobin, (B) body weight, (C) systolic blood pressure, and (D) diastolic blood pressure.

$\mathrm{Cl}$, confidence interval; IV, inverse variance; SD, standard deviation. 


\section{Effect of SGLT2 inhibitor on eGFR}

First, we compared the eGFR levels at each time point between the SGLT2 inhibitor and control. As shown in Fig. 1A, SGLT2 inhibitor treatment showed a lower eGFR level than the control at 12 weeks $(-1.81 \mathrm{~mL} / \mathrm{min}$ per $1.73 \mathrm{~m}^{2} ; 95 \%$ confidence interval [CI] -3.03 to -0.58$)$ and at 24 weeks $\left(-1.33 \mathrm{~mL} / \mathrm{min}\right.$ per $1.73 \mathrm{~m}^{2} ; 95 \% \mathrm{CI},-2.52$ to -0.15). However, a favorable effect on eGFR was observed after at least 156 weeks of treatment. At 208 weeks of treatment, the mean difference in eGFR was $3.96 \mathrm{~mL} /$ min per $1.73 \mathrm{~m}^{2}$ (95\% CI, 3.13-4.80) between groups. In general, the improving trend of eGFR was observed in the SGLT2 inhibitor group as the treatment duration was prolonged. In terms of eGFR change from baseline, the mean difference was $1.42 \mathrm{~mL} / \mathrm{min}$ per $1.73 \mathrm{~m}^{2}$ (95\% CI, 0.42 to 2.41) at 156 weeks (Fig. 1B). Therefore, SGLT2 inhibitor treatment showed reno-protective effects after long-term treatment.

\section{Effects of SGLT2 inhibitor on glycosylated hemoglobin, body weight, and blood pressure}

The glucose-lowering effect of SGLT2 inhibitors was consistently observed: the mean difference in the decline of the glycosylated hemoglobin (HbAlc) was -0.54 (95\% CI, -0.67 to -0.41$)$ at 52 weeks and $-0.62(95 \% \mathrm{CI},-0.75$ to -0.48 ) at 104 weeks, respectively (Fig. $2 \mathrm{~A}$ ). The magnitude of body weight reduction was also greater in the SGLT2 inhibitor treatment than control treatment group (Fig. 2B). Both the systolic and diastolic blood pressure were more significantly decreased in the SGLT2 inhibitor treatment (Fig. 2C, D).

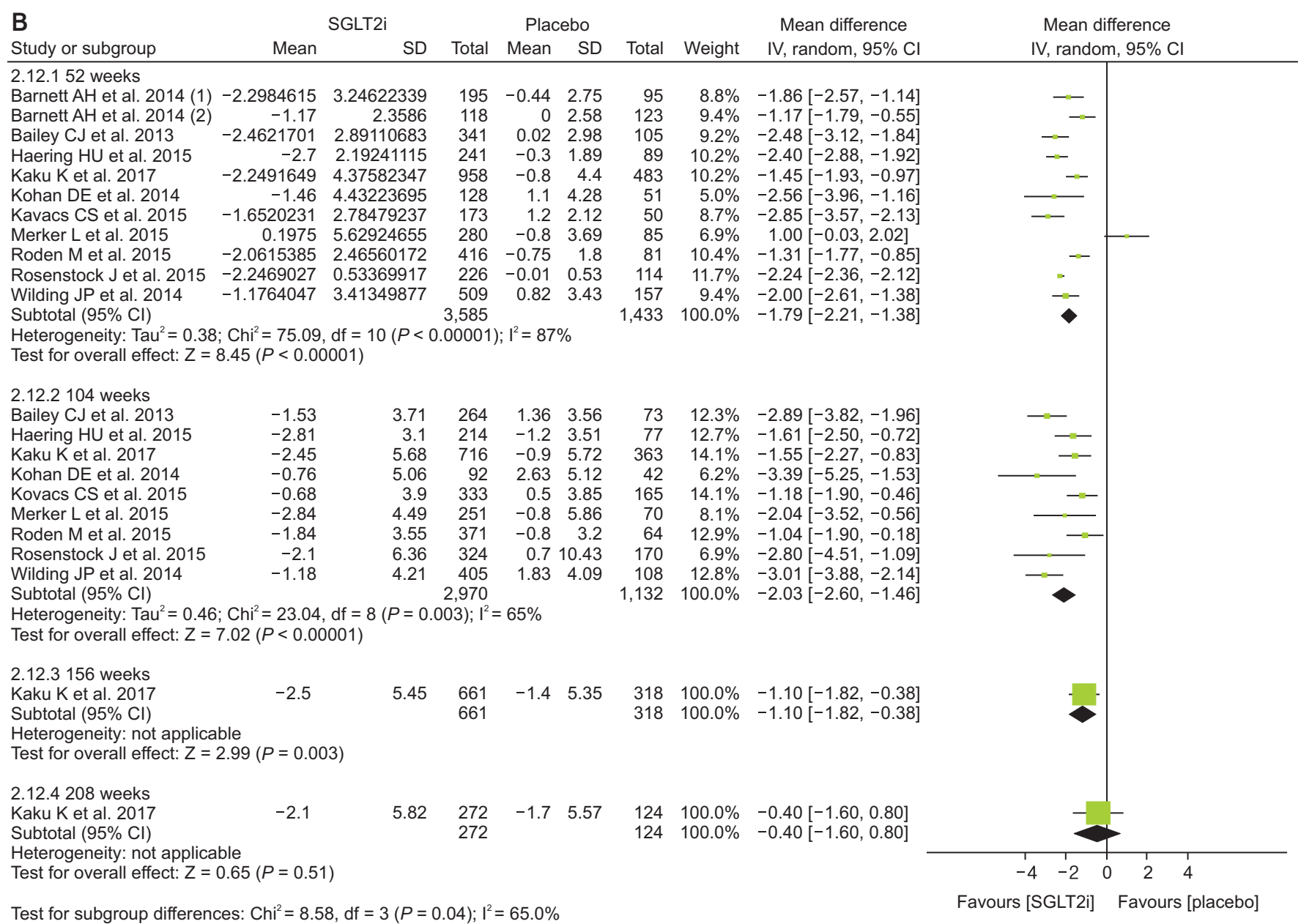

Figure 2. Continued 1. 


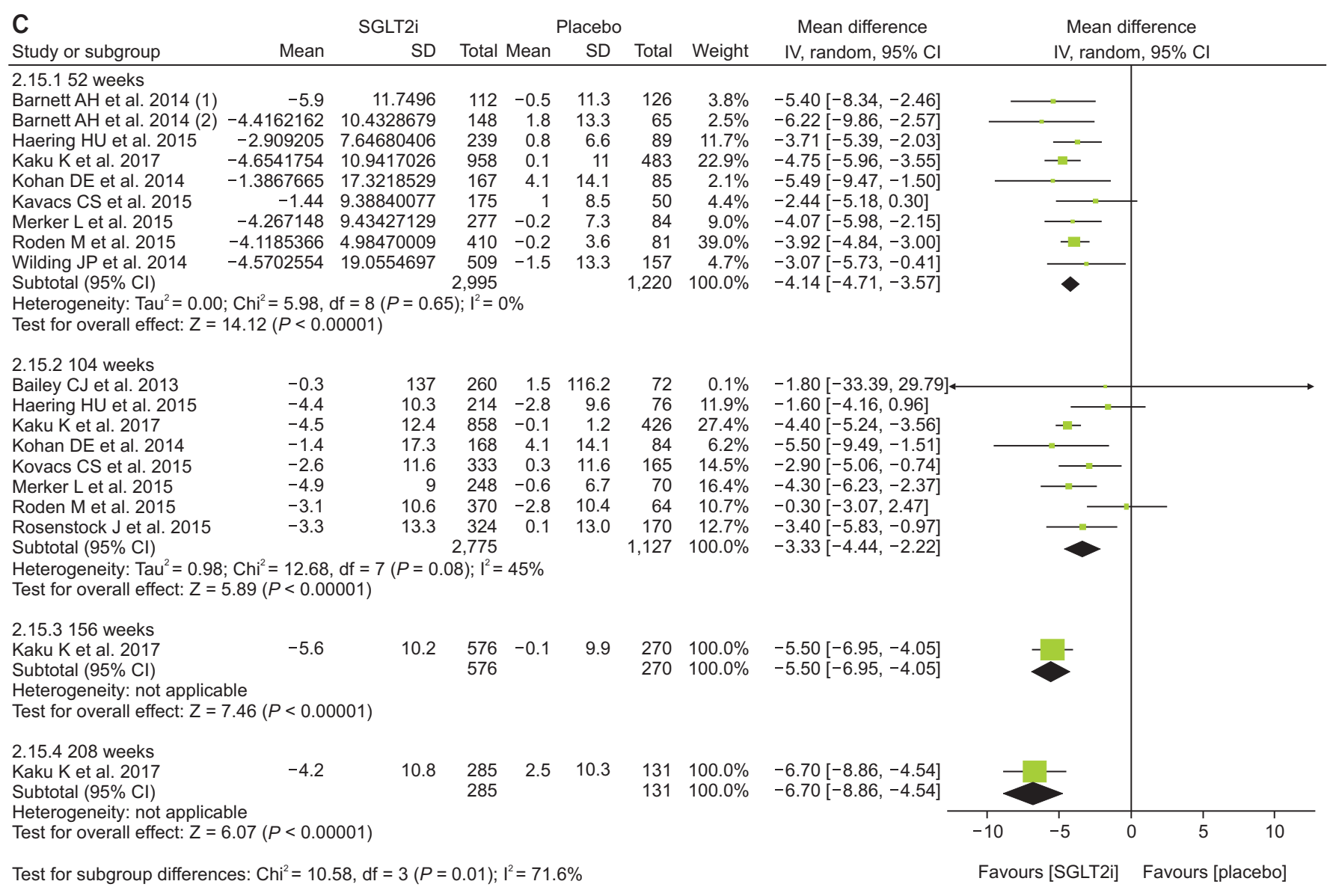

Figure 2. Continued 2.

\section{Adverse effects of SGLT2 inhibitor}

There was no difference between the SGLT2 inhibitor and control groups in hypoglycemia events and urinary tract infection (Fig. 3A, B). However, more subjects were diagnosed with genital infections (risk ratio [RR], 3.34) (Fig. 3C) and diabetic ketoacidosis (RR, 2.22) (Fig. 3D). Acute kidney injury was less in the SGLT2 inhibitor group than in the control group (RR, 0.71) (Fig. 3E), but volume depletion was slightly more common in the SGLT2 inhibitor group (RR, 1.16) (Fig. 3F).

\section{Effects of SGLT2 inhibitor on renal function among} patients with eGFRs of less than $60 \mathrm{~mL} / \mathrm{min}$ per $1.73 \mathrm{~m}^{2}$

The clinical studies we included for this systemic review and meta-analysis did not enroll a sufficient number of patients with eGFRs of less than $60 \mathrm{~mL} / \mathrm{min}$ per 1.73 $\mathrm{m}^{2}$. The patients with eGFRs of less than $60 \mathrm{~mL} / \mathrm{min}$ per
$1.73 \mathrm{~m}^{2}$ included $7.4 \%$ of participants in the dapagliflozin study (DECLARE-TIMI 58) and $25.5 \%$ of participants in the empagliflozin study (EMPA-REG). Dapagliflozin did not demonstrate the prevention of eGFR decline in patients with eGFRs of less than $60 \mathrm{~mL} / \mathrm{min}$ per 1.73 $\mathrm{m}^{2}$ compared to the placebo group during four years of follow-up $(P=0.053)$ [11]. This negative result for preventing eGFR decline with dapagliflozin could be due to the insufficient number of enrolled patients with eGFRs of less than $60 \mathrm{~mL} / \mathrm{min}$ per $1.73 \mathrm{~m}^{2}$ since dapagliflozin reduced the rate of eGFR decline in patients with eGFRs of more than $60 \mathrm{~mL} / \mathrm{min}$ per $1.73 \mathrm{~m}^{2}$. In the empagliflozin study, patients with eGFRs of less than $60 \mathrm{~mL} / \mathrm{min}$ per $1.73 \mathrm{~m}^{2}$ treated with empagliflozin showed higher eGFRs compared to the placebo group from 156 weeks, while the analysis with total enrolled patients showed higher eGFRs at 104 weeks (Fig. 4A vs. Fig. 1A). In terms of the eGFR change from baseline, SGLT2 inhibitors showed a beneficial effect at 208-week treatment compared to 


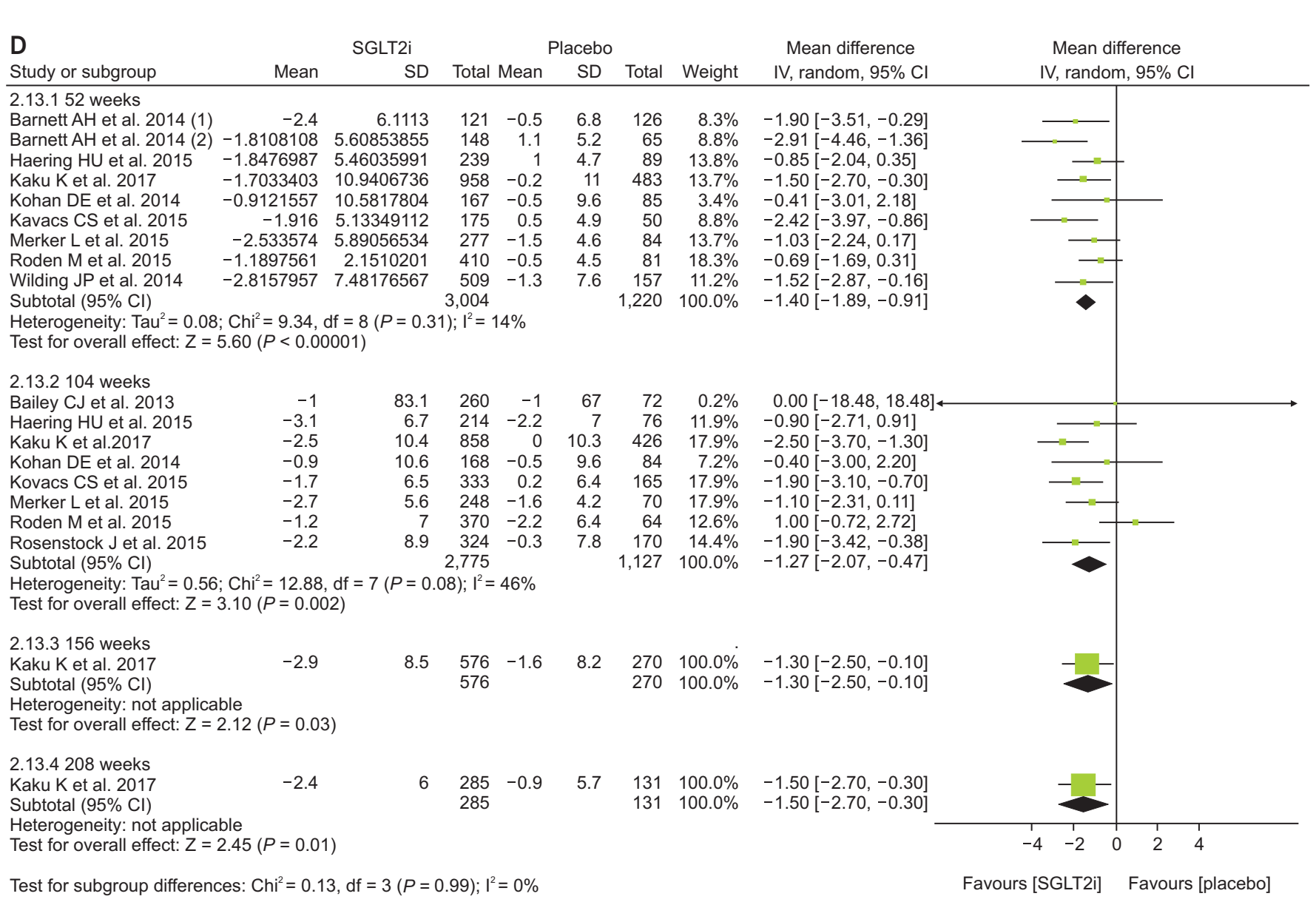

Figure 2. Continued 3.

the control group (Fig. 4B). Both SGLT2 inhibitor studies revealed the initial decrease of the eGFR after SGLT2 inhibitors treatment since the mechanism of SGLT2 inhibitors may be due to relieving vasodilation of the afferent arteriole and following decrease of glomerular hyperfiltration in diabetes [31]. This initial decrease of the eGFR after SGLT2 inhibitor treatment was more significant in patients with eGFRs of less than $60 \mathrm{~mL} / \mathrm{min}$ per $1.73 \mathrm{~m}^{2}$.

The risk of a sustained decrease in eGFR by at least $40 \%$ to less than $60 \mathrm{~mL} / \mathrm{min}$ per $1.73 \mathrm{~m}^{2}$, ESRD, or renal death was lower in the dapagliflozin group than those in the placebo group, but there was no statistical significance in patients with eGFRs of less than $60 \mathrm{~mL} / \mathrm{min}$ per $1.73 \mathrm{~m}^{2}$ (hazard ratio, $0.60 ; 95 \% \mathrm{CI}, 0.35$ to $1.02 ; P=0.059$ ) [11]. In the EMPA-REG study, incident or worsening nephropathy was significantly lower in the empagliflozin group with eGFRs of less than $60 \mathrm{~mL} / \mathrm{min}$ per $1.73 \mathrm{~m}^{2}$ than in the placebo group (hazard ratio, 0.58 ; $95 \% \mathrm{CI}, 0.47$ to 0.71 ; $P<0.001$ ) [10]. The adverse events in the EMPA-REG study were similar between the empagliflozin group and the placebo group in patients with eGFRs of $60 \mathrm{~mL} / \mathrm{min}$ per $1.73 \mathrm{~m}^{2}$ or more and in patients with eGFRs of $59 \mathrm{~mL} /$ min per $1.73 \mathrm{~m}^{2}$ or less. In our meta-analysis, patients with eGFRs of less than $60 \mathrm{~mL} / \mathrm{min}$ per $1.73 \mathrm{~m}^{2}$ showed less hypoglycemia and more genital infections in SGLT2 inhibitor treatment compared to the control (Supplementary Fig. 2).

\section{Results of Asian-dominant research}

We arbitrarily defined Asian-dominant when Asians made up more than $40 \%$ of the total subjects. Kaku et al [21] analyzed the subgroup data of the Asian population from the EMPA-REG OUTCOME trial, which was the longest and largest trial included in our meta-analysis. Asian-dominant studies showed no significant difference in eGFR change between groups (Fig. 5A). Only one study was analyzed after 156 weeks of treatment in this meta- 


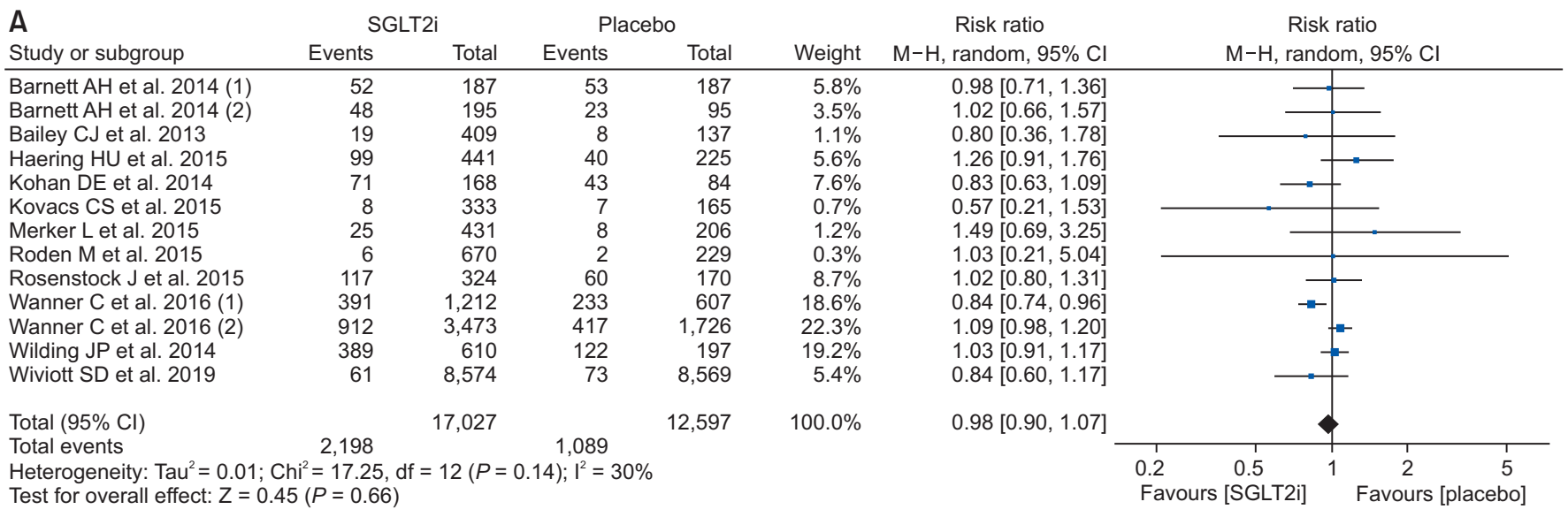

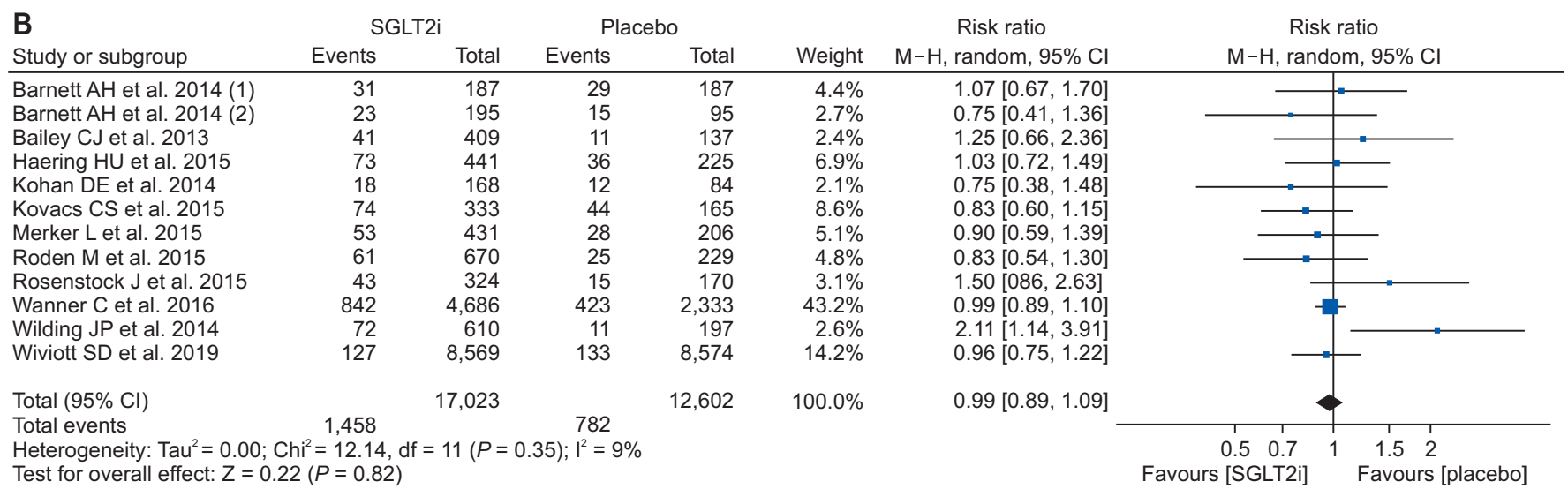

\begin{tabular}{|c|c|c|c|c|c|c|c|c|c|c|}
\hline \multirow{2}{*}{$\begin{array}{l}\text { C } \\
\text { Study or subgroup }\end{array}$} & \multicolumn{2}{|c|}{ SGLT2i } & \multicolumn{2}{|c|}{ Placebo } & \multirow[b]{2}{*}{ Weight } & \multicolumn{2}{|l|}{ Risk ratio } & \multirow{2}{*}{\multicolumn{2}{|c|}{$\begin{array}{l}\text { Risk ratio } \\
\mathrm{M}-\mathrm{H}, \text { random, } 95 \% \mathrm{Cl}\end{array}$}} & \\
\hline & Events & Total & Events & Total & & $\mathrm{M}-\mathrm{H}$, random, $95 \% \mathrm{Cl}$ & & & & \\
\hline Barnett AH et al. 2014 (1) & 5 & 187 & 2 & 187 & $3.2 \%$ & $2.50[0.49,12.72]$ & & & & \\
\hline Barnett AH et al. 2014 (2) & 12 & 195 & 6 & 95 & $7.4 \%$ & $0.97[0.38,2.52]$ & & & & \\
\hline Bailey CJ et al. 2013 & 53 & 409 & 7 & 137 & $9.7 \%$ & $2.54[1.18,5.45]$ & & & & \\
\hline Haering HU et al. 2015 & 23 & 441 & 2 & 225 & $3.9 \%$ & $5.87[1.40,24.66]$ & & & & \\
\hline Kohan DE et al. 2014 & 15 & 168 & 3 & 84 & $5.2 \%$ & $2.50[0.74,8.40]$ & & & & \\
\hline Kovacs CS et al. 2015 & 24 & 333 & 5 & 165 & $7.4 \%$ & $2.38[0.92,6.12]$ & & & & \\
\hline Merker L et al. 2015 & 38 & 431 & 1 & 206 & $2.3 \%$ & $18.16[2.51,131.37]$ & & & & \\
\hline Roden M et al. 2015 & 29 & 670 & 4 & 229 & $6.6 \%$ & $2.48[0.88,6.97]$ & & & & \\
\hline Rosenstock J et al. 2015 & 21 & 324 & 3 & 170 & $5.3 \%$ & $3.67[1.11,12.14]$ & & & & \\
\hline Wanner C et al. 2016 (1) & 64 & 1,212 & 10 & 607 & $11.4 \%$ & $3.21[1.66,6.20]$ & & & $\longrightarrow$ & \\
\hline Wanner C et al. 2016 (2) & 234 & 3,473 & 32 & 1,726 & $17.7 \%$ & $3.63[2.52,5.23]$ & & & & \\
\hline Wilding JP et al. 2014 & 70 & 610 & 6 & 197 & $9.0 \%$ & $3.77[1.66,8.54]$ & & & & \\
\hline Wiviott SD et al. 2019 & 76 & 8,574 & 9 & 8,569 & $10.9 \%$ & $8.44[4.23,16.83]$ & & & & \\
\hline Total $(95 \% \mathrm{Cl})$ & & 17,027 & & 12,597 & $100.0 \%$ & $3.34[2.44,4.57]$ & & & & \\
\hline \multirow{2}{*}{\multicolumn{7}{|c|}{$\begin{array}{l}\text { Heterogeneity: } \mathrm{Tau}^{2}=0.11 ; \mathrm{Chi}^{2}=19.17, \mathrm{df}=12(P=0.08) ; \mathrm{I}^{2}=37 \% \\
\text { Test for overall effect: } Z=7.57(P<0.00001)\end{array}$}} & 0.01 & 0.1 & 1 & 100 \\
\hline & & & & & & & & s [SGLT2i] & Favours [ & bo] \\
\hline
\end{tabular}

\begin{tabular}{|c|c|c|c|c|c|c|c|c|c|c|}
\hline \multirow{2}{*}{$\begin{array}{l}\text { D } \\
\text { Study or subgroup }\end{array}$} & \multicolumn{2}{|c|}{ SGLT2i } & \multicolumn{2}{|c|}{ Placebo } & \multirow[b]{2}{*}{ Weight } & \multirow{2}{*}{\multicolumn{2}{|c|}{$\begin{array}{l}\text { Risk ratio } \\
\mathrm{M}-\mathrm{H}, \text { random, } 95 \% \mathrm{Cl}\end{array}$}} & \multirow{2}{*}{\multicolumn{2}{|c|}{$\begin{array}{l}\text { Risk ratio } \\
\mathrm{M}-\mathrm{H} \text {, random, } 95 \% \mathrm{Cl}\end{array}$}} & \\
\hline & Events & Total & Events & Total & & & & & & \\
\hline Wanner C et al. 2016 & 4 & 4,685 & 1 & 2,333 & $8.8 \%$ & $1.99[0.22,17.81]$ & & & & \\
\hline Wiviott SD et al. 2019 & 27 & 8,574 & 12 & 8,569 & $91.2 \%$ & $2.25[1.14,4.44]$ & & & - & \\
\hline Total $(95 \% \mathrm{Cl})$ & & 13,259 & & 10,902 & $100.0 \%$ & $2.22[1.16,4.26]$ & & & & \\
\hline \multirow{2}{*}{\multicolumn{7}{|c|}{$\begin{array}{l}\text { Heterogeneity: } \mathrm{Tau}^{2}=0.00 ; \mathrm{Chi}^{2}=0.01, \mathrm{df}=1(P=0.92) ; \mathrm{I}^{2}=0 \% \\
\text { Test for overall effect: } Z=2.42(P=0.02)\end{array}$}} & 0.01 & 0.1 & 10 & 100 \\
\hline & & & & & & & & Irs [SGLT2i] & Favours [p & bo] \\
\hline
\end{tabular}

Figure 3. Effect of sodium-glucose cotransporter-2 inhibitors (SGLT2i) on (A) hypoglycemia, (B) urinary tract infection, (C) genital infection, (D) diabetic ketoacidosis, (E) acute kidney injury, and (F) volume depletion.

$\mathrm{Cl}$, confidence interval; M-H, Mantel-Haenszel. 


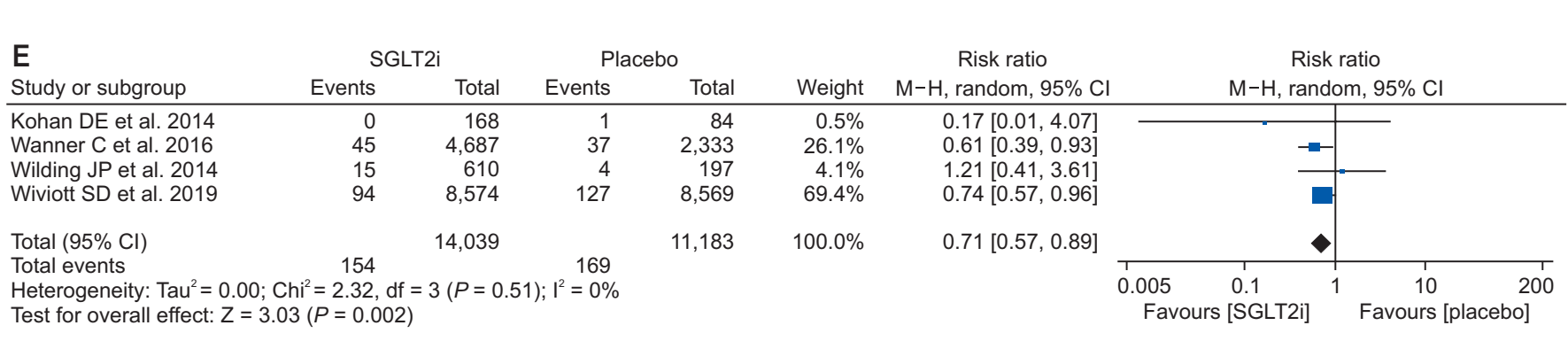

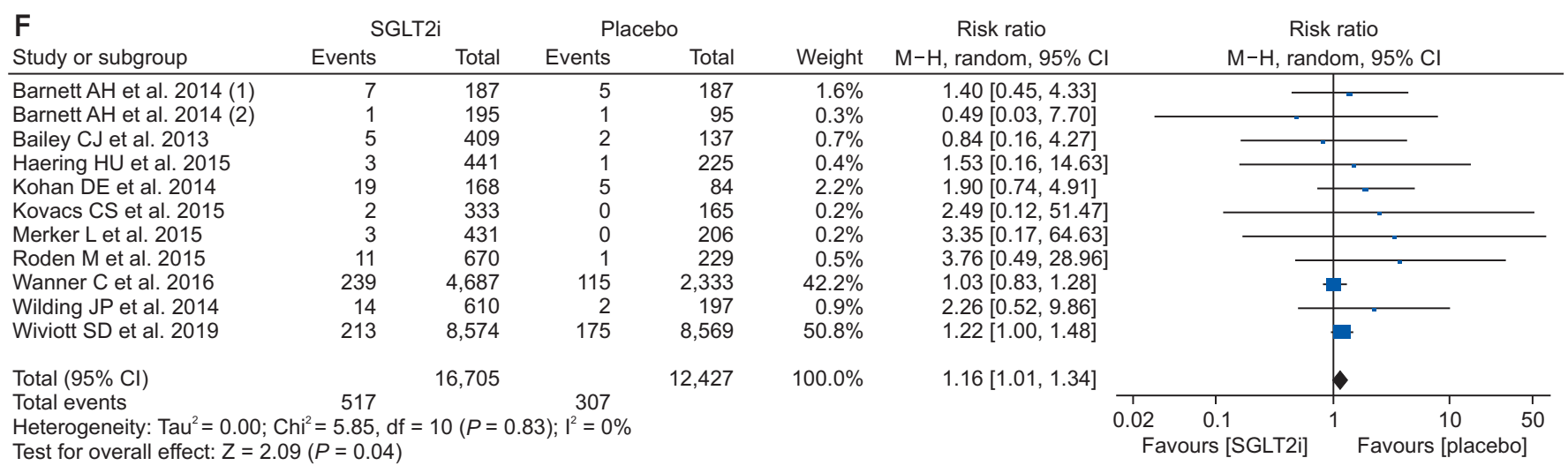

Figure 3. Continued.

analysis; therefore, it is not conclusive as to whether Asians may experience similar benefits of renal preservation with long-term treatment of SGLT2 inhibitors compared to the non-Asian population. Other parameters, such as HbAlc, body weight, blood pressure, and adverse events were similar with meta-analysis of the total population (Fig. 5B and Supplementary Fig. 3).

\section{Korean Diabetes Association and Korean Society of Nephrology joint consensus statement on the use of SGLT2 inhibitor in T2DM for preservation of renal function}

Long-term treatment of SGLT2 inhibitor has a preventive effect on decline of renal function in some patients with T2DM; therefore, long-term treatment of SGLT2 inhibitors is recommended under continuous monitoring of renal function (i.e., eGFR) (weak recommendation, low quality of evidence).

\section{Strength of the recommendation}

Study participants were mainly from Western countries. Their baseline body mass index was near $30 \mathrm{~kg} / \mathrm{m}^{2}$, which is relatively higher than that of Korean subjects with
T2DM. Furthermore, Asian-dominant studies are lacking and a meta-analysis including only Asian-dominant studies did not show statistically significant effects on renal preservation. In addition, only two studies included subjects whose eGFRs were less than $60 \mathrm{~mL} / \mathrm{min} / 1.73 \mathrm{~m}^{2}$ in this analysis. The immediate decline in renal function was frequently observed in subjects with eGFRs of less than $60 \mathrm{~mL} / \mathrm{min}$ per $1.73 \mathrm{~m}^{2}$; therefore, more attention should be paid to this population. In this regard, we cannot recommend the use of SGLT2 inhibitors in all patients with T2DM: more studies assessing renal effects as a primary outcome and including a meaningful number of Asian patients and subjects with a broad range of renal function are necessary. However, the ongoing Dapagliflozin And Prevention of Adverse Outcomes in Chronic Kidney Disease (DAPA-CKD) trial (NCT03036150) and EMPA-KIDNEY study (NCT03594110) are likely to provide further evidence in this field. This recommendation can be revised and updated after publication of these two landmark studies.

\section{Quality of evidence}

The authors independently assessed the risk of bias at the study level using the revised Cochrane risk-of-bias 


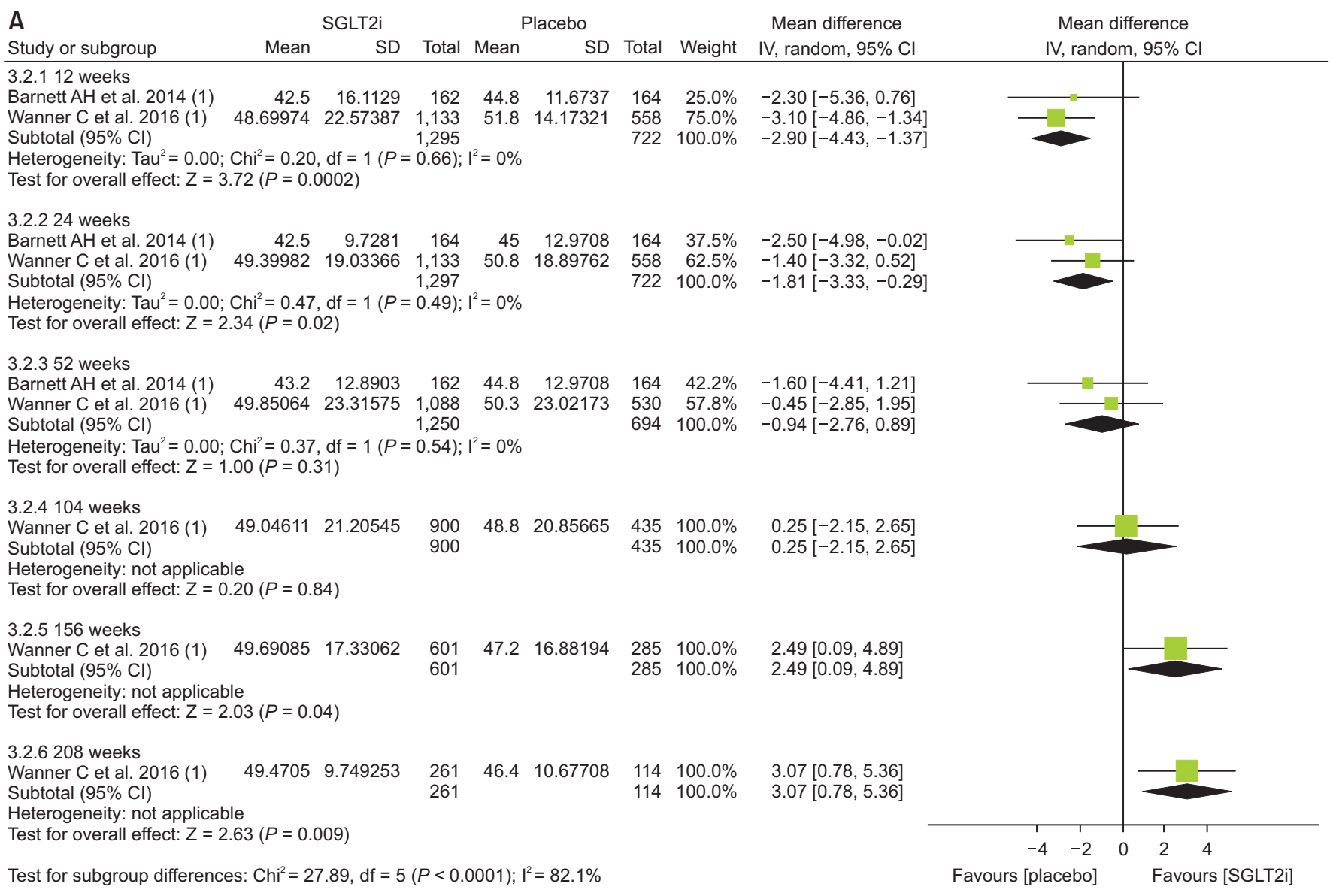

Figure 4. Results of patients with estimated glomerular filtration rate (eGFR) below $60 \mathrm{~mL} / \mathrm{min} / 1.73 \mathrm{~m}^{2}$. Effect of sodium-glucose cotransporter-2 inhibitors (SGLT2i) on (A) eGFR, and (B) change of eGFR from baseline.

$\mathrm{Cl}$, confidence interval; IV, inverse variance; SD, standard deviation.

tool for randomized trials (risk of bias 2.0; Cochrane, London, England) and any disagreements were resolved by establishing a consensus among the authors. The risk of bias was generally low except in two studies that showed high risks of bias due to missing outcomes data (Supplementary Fig. 3). A large number of patients were not followed up with at the time of final assessment. More than $50 \%$ of participants were not followed up with in three out of 10 studies. We also do not know the distinct clinical characteristics of subjects who were followed up with successfully and those who were not. Therefore, a degree of uncertainty exists due to the high dropout rate.

\section{Other considerations}

The mainstay of prevention and treatment for CKD in T2DM included optimal treatment of hyperglycemia, dyslipidemia, obesity, and blood pressure using RAAS block- ade. These general recommendations should be followed and the patient's preferences regarding both the benefits of SGLT2 inhibitors and their possible disadvantages, such as urinary frequency, unwanted body weight loss, genital infections, and cost, should be considered. We should educate patients for preventing volume depletion and genital infection. From the physician's perspective, an immediate decline in renal function is concerned, and a follow-up plan for monitoring eGFR must be developed.

\section{Conflicts of interest}

All authors have no conflicts of interest to declare.

\section{Acknowledgments}

This work was performed through the cooperation of 


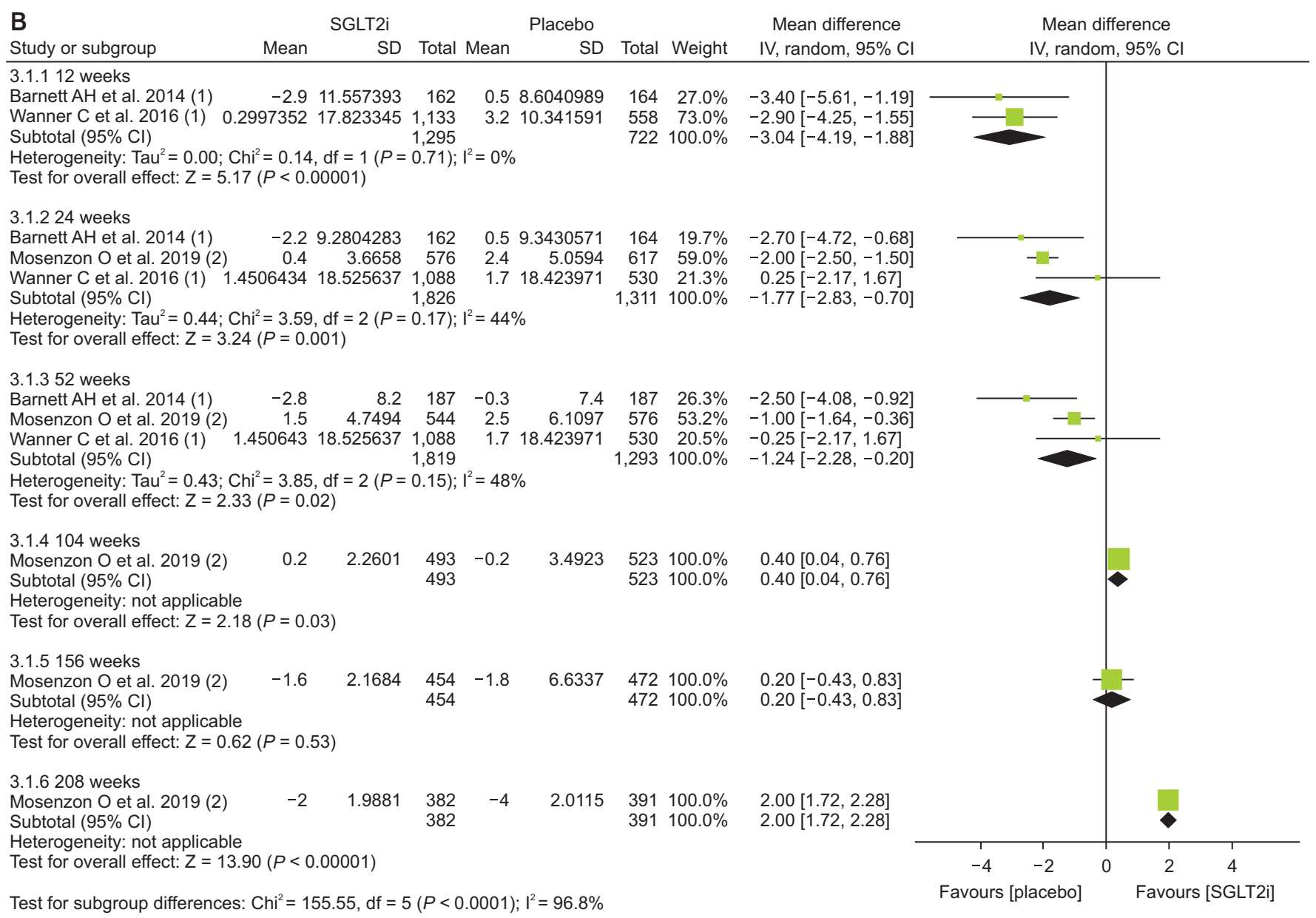

Figure 4. Continued.

the Korean Diabetes Association and the Korean Society of Nephrology.

\section{Authors' contributions}

Tae Jung Oh, Ju-Young Moon, and Min Kyong Moon participated in the data collection and wrote the manuscript. Kyu Yeon Hur, Seung Hyun Ko, and Hyun Jung Kim participated in the study design and performed the statistical analysis. Tae Jung Oh, Ju-Young Moon, Kyu Yeon Hur, Seung Hyun Ko, Hyun Jung Kim, Taehee Kim, Dong Won Lee, and Min Kyong Moon participated in the conception, analysis, and interpretation of data. Seung Hyun Ko and Dong Won Lee participated in the study design and coordination and helped to draft the manuscript. All authors read and approved the final manuscript.

\section{References}

[1] Jin DC, Yun SR, Lee SW, Han SW, Kim W, Park J. Current characteristics of dialysis therapy in Korea: 2015 registry data focusing on elderly patients. Kidney Res Clin Pract 2016;35:204-211.

[2] Jin DC. Major changes and improvements of dialysis therapy in Korea: review of end-stage renal disease registry. Korean J Intern Med 2015;30:17-22.

[3] Jin DC, Yun SR, Lee SW, et al. Lessons from 30 years' data of Korean end-stage renal disease registry, 1985-2015. Kidney Res Clin Pract 2015;34:132-139.

[4] Jin DC, Yun SR, Lee SW, et al. Current characteristics of dialysis therapy in Korea: 2016 registry data focusing on diabetic patients. Kidney Res Clin Pract 2018;37:20-29.

[5] American Diabetes Association. 10. Microvascular complications and foot care: standards of medical care in diabetes-2018. Diabetes Care 2018;41(Suppl 1):S105-S118. 


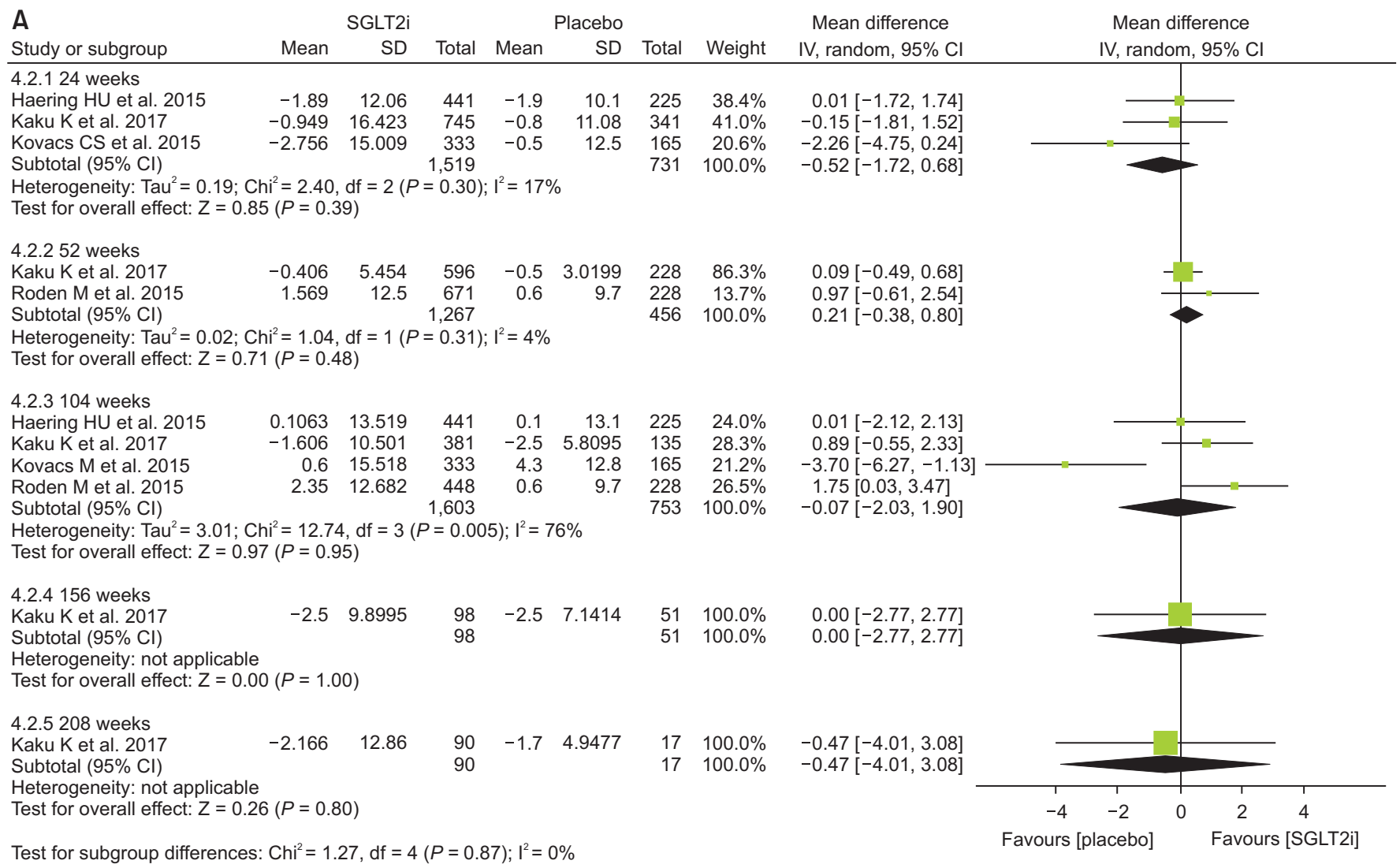

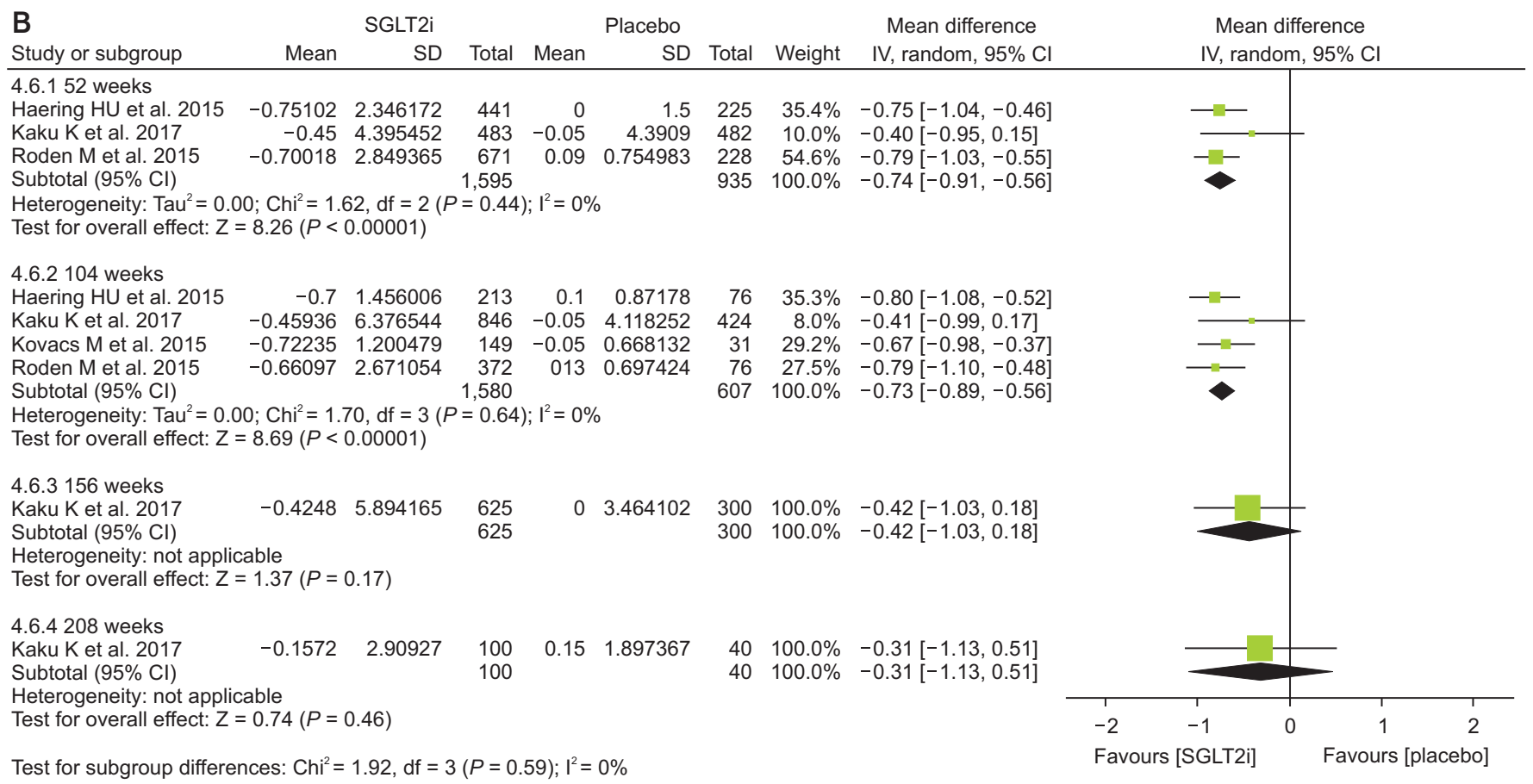

Figure 5. Result of Asian dominant studies. Effects of sodium-glucose cotransporter-2 inhibitors (SGLT2i) on change of (A) estimated glomerular filtration rate and (B) glycosylated hemoglobin.

$\mathrm{Cl}$, confidence interval; IV, inverse variance; SD, standard deviation. 
[6] Go AS, Chertow GM, Fan D, McCulloch CE, Hsu CY. Chronic kidney disease and the risks of death, cardiovascular events, and hospitalization. N Engl J Med 2004;351:12961305.

[7] Zinman B, Wanner C, Lachin JM, et al.; EMPA-REG OUTCOME Investigators. Empagliflozin, cardiovascular outcomes, and mortality in type 2 diabetes. N Engl J Med 2015; 373:2117-2128.

[8] Neal B, Perkovic V, Mahaffey KW, et al.; CANVAS Program Collaborative Group. Canagliflozin and cardiovascular and renal events in type 2 diabetes. N Engl J Med 2017;377:644657.

[9] Wiviott SD, Raz I, Bonaca MP, et al.; DECLARE-TIMI 58 Investigators. Dapagliflozin and cardiovascular outcomes in type 2 diabetes. N Engl J Med 2019;380:347-357.

[10] Wanner C, Inzucchi SE, Lachin JM, et al.; EMPA-REG OUTCOME Investigators. Empagliflozin and progression of kidney disease in type 2 diabetes. $N$ Engl J Med 2016;375:323334.

[11] Mosenzon O, Wiviott SD, Cahn A, et al. Effects of dapagliflozin on development and progression of kidney disease in patients with type 2 diabetes: an analysis from the DECLARE-TIMI 58 randomised trial. Lancet Diabetes Endocrinol 2019;7:606-617.

[12] Perkovic V, Jardine MJ, Neal B, et al.; CREDENCE Trial Investigators. Canagliflozin and renal outcomes in type 2 diabetes and nephropathy. N Engl J Med 2019;380:2295-2306.

[13] Lee JY, Cho Y, Lee M, et al. Predictors of the therapeutic efficacy and consideration of the best combination therapy of sodium-glucose co-transporter 2 inhibitors. Diabetes Metab J 2019;43:158-173.

[14] Hong AR, Koo BK, Kim SW, Yi KH, Moon MK. Efficacy and safety of sodium-glucose cotransporter-2 inhibitors in Korean patients with type 2 diabetes mellitus in real-world clinical practice. Diabetes Metab J 2019;43:590-606.

[15] American Diabetes Association. 11. Microvascular complications and foot care: standards of medical care in diabetes-2019. Diabetes Care 2019;42(Suppl 1):S124-S138.

[16] American Diabetes Association. 11. Microvascular complications and foot care: standards of medical care in diabetes-2020. Diabetes Care 2020;43(Suppl 1):S135-S151.

[17] Diabetes Canada Clinical Practice Guidelines Expert Committee, McFarlane P, Cherney D, Gilbert RE, Senior P. Chronic kidney disease in diabetes. Can J Diabetes 2018;42 Suppl 1:S201-S209.

[18] Kim MK, Ko SH, Kim BY, et al.; Committee of Clinical Prac- tice Guidelines, Korean Diabetes Association. 2019 Clinical practice guidelines for type 2 diabetes mellitus in Korea. Diabetes Metab J 2019;43:398-406.

[19] Neuen BL, Young T, Heerspink HJL, et al. SGLT2 inhibitors for the prevention of kidney failure in patients with type 2 diabetes: a systematic review and meta-analysis. Lancet Diabetes Endocrinol 2019;7:845-854.

[20] Zelniker TA, Wiviott SD, Raz I, et al. SGLT2 inhibitors for primary and secondary prevention of cardiovascular and renal outcomes in type 2 diabetes: a systematic review and meta-analysis of cardiovascular outcome trials. Lancet 2019;393:31-39.

[21] Kaku K, Lee J, Mattheus M, Kaspers S, George J, Woerle HJ; EMPA-REG OUTCOME ${ }^{\circledR}$ Investigators. Empagliflozin and cardiovascular outcomes in Asian patients with type 2 diabetes and established cardiovascular disease - results from EMPA-REG OUTCOME ${ }^{\circledR}$. Circ J 2017;81:227-234.

[22] Barnett AH, Mithal A, Manassie J, et al; EMPA-REG RENAL trial investigators. Efficacy and safety of empagliflozin added to existing antidiabetes treatment in patients with type 2 diabetes and chronic kidney disease: a randomised, double-blind, placebo-controlled trial. Lancet Diabetes Endocrinol 2014;2:369-384.

[23] Bailey CJ, Gross JL, Hennicken D, Iqbal N, Mansfield TA, List JF. Dapagliflozin add-on to metformin in type 2 diabetes inadequately controlled with metformin: a randomized, double-blind, placebo-controlled 102-week trial. BMC Med 2013;11:43.

[24] Haering HU, Merker L, Christiansen AV, et al; EMPA-REG EXTEND $^{\mathrm{rm}}$ METSU investigators. Empagliflozin as add-on to metformin plus sulphonylurea in patients with type 2 diabetes. Diabetes Res Clin Pract 2015;110:82-90.

[25] Kohan DE, Fioretto P, Tang W, List JF. Long-term study of patients with type 2 diabetes and moderate renal impairment shows that dapagliflozin reduces weight and blood pressure but does not improve glycemic control. Kidney Int 2014;85:962-971.

[26] Kovacs CS, Seshiah V, Merker L, et al.; EMPA-REG EXTEND $^{\mathrm{Tm}}$ PIO investigators. Empagliflozin as add-on therapy to pioglitazone with or without metformin in patients with type 2 diabetes mellitus. Clin Ther 2015;37:1773-1788.e1.

[27] Merker L, Häring HU, Christiansen AV, et al.; EMPA-REG EXTEND MET investigators. Empagliflozin as add-on to metformin in people with type 2 diabetes. Diabet Med 2015;32:1555-1567.

[28] Roden M, Merker L, Christiansen AV, et al; EMPA-REG EX- 
TEND $^{\mathrm{Tm}}$ MONO investigators. Safety, tolerability and effects on cardiometabolic risk factors of empagliflozin monotherapy in drug-naïve patients with type 2 diabetes: a doubleblind extension of a phase III randomized controlled trial. Cardiovasc Diabetol 2015;14:154.

[29] Rosenstock J, Jelaska A, Zeller C, Kim G, Broedl UC, Woerle HJ; EMPA-REG BASALTM trial investigators. Impact of empagliflozin added on to basal insulin in type 2 diabetes inadequately controlled on basal insulin: a 78-week ran- domized, double-blind, placebo-controlled trial. Diabetes Obes Metab 2015;17:936-948.

[30] Wilding JP, Woo V, Rohwedder K, Sugg J, Parikh S; Dapagliflozin 006 Study Group. Dapagliflozin in patients with type 2 diabetes receiving high doses of insulin: efficacy and safety over 2 years. Diabetes Obes Metab 2014;16:124-136.

[31] Fioretto P, Zambon A, Rossato M, Busetto L, Vettor R. SGLT2 inhibitors and the diabetic kidney. Diabetes Care 2016;39 Suppl 2:S165-S171. 